\title{
Evaluation of Ignition Method for Determining Asphalt Content of Hot Mix Asphalt Mixtures
}

\author{
Mohammed Y. Taha \\ Assistant Professor-University of Mosul-Engineering College
}

\begin{abstract}
The asphalt content of an asphalt mixture, as binder, is an important physical characteristics and influences the performance life of flexible pavements. Traditionally, in Iraq the asphalt content has been measured in laboratory by extraction from the mixture with chemical solvents. Recently, a new technology, known as the ignition method, has been developed to eliminate the need for these harmful solvents and to make the laboratory more safer. The main objective of this work was to evaluate and use the ignition test method to determine asphalt content and aggregate gradation in hot mix asphalt mixtures. An extensive laboratory work was conducted to meet this objective, which involving more than 300 samples of asphalt mixture, with five asphalt contents and two types of aggregate of three types of gradation, were prepared and tested using ignition and extraction methods.

Data from ten laboratories was analyzed and used to determine the accuracy and precision of this test method. The study results and statistical analysis have show that the ignition method can be used to accurately and quickly determine the asphalt content and aggregate gradation of asphalt mixtures with same, if not greater, precision than the extraction method.
\end{abstract}

Key Words: asphalt content, ignition test, hot-mix asphalt, statistical analysis

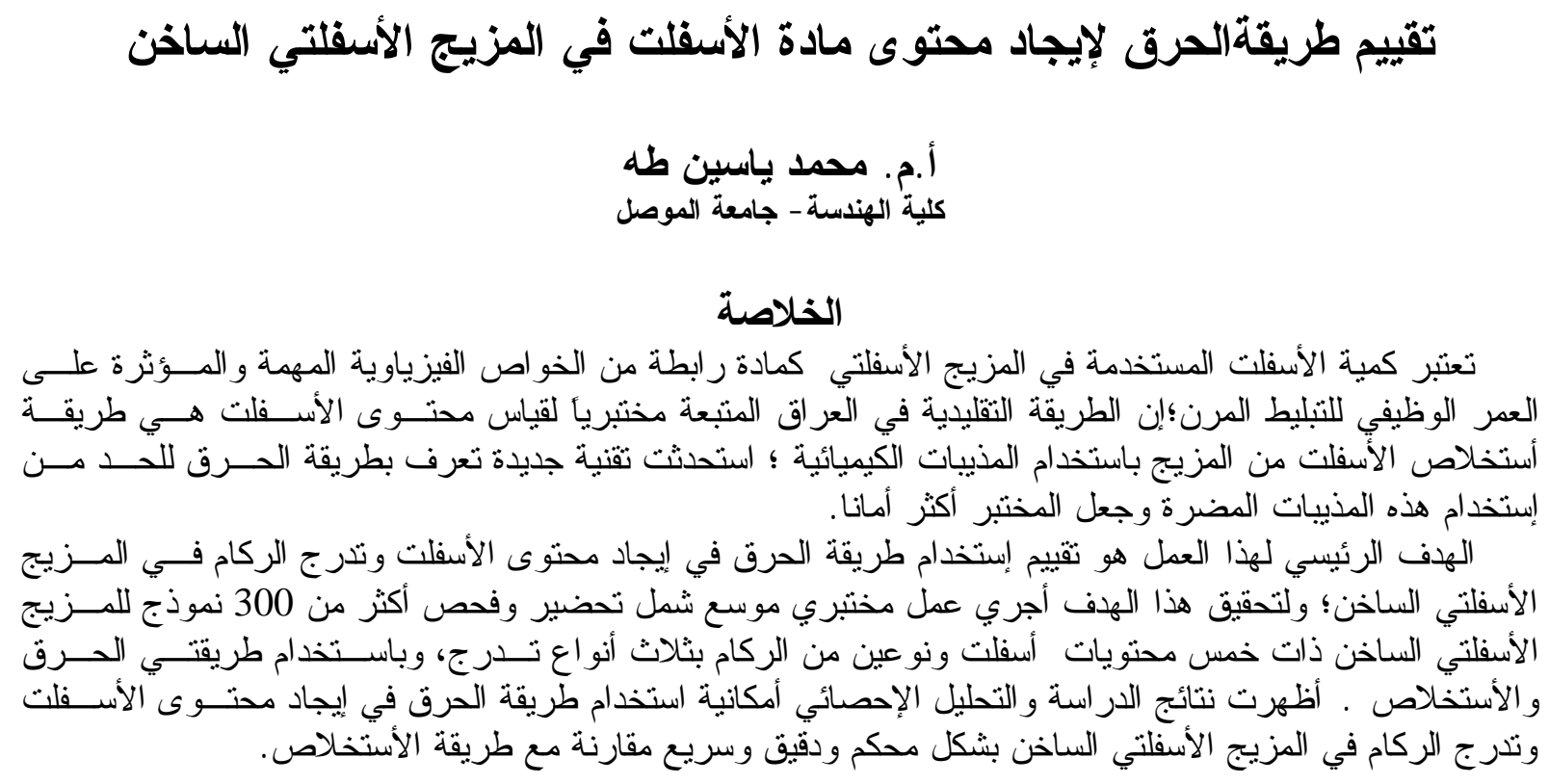




\section{Introduction}

Hot-mix asphalt (HMA) plays a vital role in the Iraqi roadway pavement system and will continue to do so into the next years. Asphalt is a mixture of many chemical types. It is a variable material which has a significant effect on the HMA properties and their applications[1,2].

Asphalt content as binder is often the most expensive fraction in the HMA mixtures, which is critical to their performance, affecting the pavement's tendency for permanent deformation, fatigue life and susceptibility to moisture damage. Therefore, the measurement of asphalt content of HMA mixture is a fundamentally important test for manufactures, contractors, researchers, and regulatory authorities[3,4].

Up until this time, the primary procedure for measuring asphalt content in Iraq is a chemical solvents extraction method. The solvents that used in this method are dangerous to human health and the environment. They are also difficult and costly to dispose of and expensive to use [5]. Recently, a new technology has been perfected by the National Center for Asphalt Technology (NCAT) [6,7]. This method uses a very high temperature oven to burn off the asphalt, and by comparing the mass of the sample before and after the burn off, the asphalt content can be found. Then, the aggregate that is left may be tested for gradation and other properties[6,8,9].

\section{Study Objective}

The main objective of this study is to evaluate the use of the ignition method in Iraqi laboratories by determining the accuracy and precision of this method for asphalt content and aggregate gradation determinations. The study consisted of comparisons of the measured asphalt content and aggregate gradation determined from laboratory prepared HMA samples using both ignition and extraction methods.

The study seeks to provide a recommended and appropriate test procedure to measure asphalt content in HMA mixtures in Iraq using ignition method, which must be compatible with the most recent American Society for Testing Materials (ASTM)[10] and American Association of State Highway and Transportation Officials (AASHTO) standard methods[11].

\section{Materials}

In this work, the HMA mixtures were prepared with two different types of aggregate (crushed gravel and limestone) and one type of asphalt cement AC-30 (penetration grade 50/60). The properties of these materials should conform to the Iraqi requirements of General Specification for Roads and Bridges[12].

Oven dried aggregate from each type was first fractionated into each sieve size and then recombined to meet the gradation in Table 1. Portland cement was used to provide the material passing the sieve No. 200 in all mix gradations. HMA samples were prepared by mixing, at $140^{\circ} \mathrm{C}$, the aggregate with the required amount of asphalt cement. Table 2 presents the aggregate type with respective gradation type used to prepare HMA samples at various asphalt contents.

Table 1. Design Gradation Of Aggregate.

\begin{tabular}{|c||c||c||c|}
\hline \multirow{2}{*}{$\begin{array}{c}\text { Sieve Size } \\
\text { Mm }\end{array}$} & Type I & Type II & Type IIIA \\
\cline { 2 - 4 } & Base Course & Binder Course & Surface Course \\
\hline 37.5 & \% Passing by Weight of Total Aggregate \\
\hline 25.0 & 100 & 100 & 100 \\
\hline 19.0 & 95 & 100 & 100 \\
\hline 12.5 & 85 & 95 & 100 \\
\hline 9.50 & 70 & 80 & 95 \\
\hline 4.75 & 60 & 70 & 85 \\
\hline 2.36 & 45 & 50 & 60 \\
\hline 0.30 & 30 & 35 & 45 \\
\hline 0.075 & 10 & 12 & 13 \\
\hline
\end{tabular}


Table 2. Distribution of HMA Samples According to Aggregate Type and Gradation at Various Asphalt Contents.

\begin{tabular}{|c||c|c||c||c||c|c||}
\hline \multirow{2}{*}{$\begin{array}{c}\text { Asphalt } \\
\text { Content } \\
\%\end{array}$} & \multicolumn{3}{c||}{ Gravel } & \multicolumn{3}{c||}{ Limestone } \\
\cline { 2 - 7 } & Type I & Type II & Type IIIA & Type I & Type II & Type IIIA \\
\hline \hline 0.0 & \multicolumn{3}{|c|}{ Number of Samples } \\
\hline 3.5 & 12 & 6 & 6 & 6 & 6 & 6 \\
\hline 4.0 & 12 & - & - & 12 & - & - \\
\hline 4.5 & 12 & 12 & 12 & 12 & 12 & 12 \\
\hline 5.0 & 12 & 12 & 12 & 12 & 12 & 12 \\
\hline 5.5 & - & 12 & 12 & 12 & 12 & 12 \\
\hline
\end{tabular}

\section{Sample Size}

The appropriate sample size required for testing by the ignition or extraction method should provide an accurate measure of asphalt content and an ample amount of aggregate after testing for gradation analysis.

For gradation analysis in ASTM and AASHTO[10,11], the standard test procedures specify the sample size varying with the nominal maximum- size of the aggregate. Most work at NCAT[6,7,9] to date has been performed with 1200 gram samples. Sample size of 1500 grams was used in this study.

\section{Tests Procedures}

A detailed test procedure for ignition method was developed based upon pervious laboratory studies at NCAT and existing AASHTO[11] procedure, Method B. Method B was used as a basis because most of the ovens in use in Iraq do not have internal balance. Chemical extraction (centrifuge) test was performed according to ASTM D 2172[10] and AASHTO T 164A[11] methods to provide a basis for comparison to ignition test. Aggregate gradations were measured on original aggregate samples and the aggregate obtained from each of the test methods that yielded clean aggregate according to ASTM C 136 and AASHTO

\section{T 27 methods.}

In this work, the ignition test was performed with a furnace having sufficient size to allow the testing of 1500 gram HMA samples. The furnace was capable to control temperature and heating time. Also, flat stainless steel pans with No.8 screen mesh were used with a solid steel pan underneath to catch any aggregate that fell through the screen mesh. These pans allowed more exposure of asphalt cement to uniform heating conditions thus reducing the required test time.

To determine estimates of the accuracy and precision of ignition method according to ASTM C 802 [10], the study chose 10 laboratories ( 3 labs. at Baghdad University, 4 labs. at Technology University, 2 labs. at Tikrit University, and 1 lab. at Kurkuk University) for ignition of the samples. For asphalt content determination and aggregate gradation analysis, each laboratory was supplied with 5 different HMA mixture type (3 replicates for each mix) consisting of different aggregate types, gradation and asphalt contents.

\section{Ignition Method}

In the ignition method[13,14,15], the asphalt content is determined from the mass of the HMA sample before and after burning using the following equation. The difference between the mass of the HMA mixture before ignition $\left(\mathrm{M}_{\mathrm{T}}\right)$ and the aggregate mass after ignition $\left(\mathrm{M}_{\mathrm{A}}\right)$ is due to removal of asphalt cement and mass loss of aggregate: 


$$
\begin{aligned}
& \begin{array}{lll}
\text { Al-Rafidain Engineering } & \text { Vol.17 } & \text { No.3 }
\end{array} \\
& \mathrm{P}_{\mathrm{AC}}=\frac{\mathrm{M}_{\mathrm{T}}-\mathrm{M}_{\mathrm{A}}}{\mathrm{M}_{\mathrm{T}}} \times \mathrm{C}_{\mathrm{F}}
\end{aligned}
$$

Where:

$\mathrm{P}_{\mathrm{AC}}:$ Percent of the measured asphalt content, and

$\mathrm{C}_{\mathrm{F}}$ : Correction factor for the aggregate mass.

For correction factor determination, three samples of each aggregate type with respective gradation type were prepared (the mass of each blank sample was $M_{B}=1500$ grams). The mass losses for three blank samples were determined by the ignition test, samples were burned at a test (optimum) temperature and time. Then, the average mass loss $\left(\mathrm{M}_{\mathrm{L}}\right)$ was calculated and the following equation was used to determine the correction factor $\mathrm{C}_{\mathrm{F}}$ for each aggregate:

$$
\mathrm{C}_{\mathrm{F}}=1 \text { - } \frac{\mathrm{M}_{\mathrm{L}}}{------}
$$

\section{Selection of Test Temperature and Time:}

The preliminary study was performed in the laboratory to evaluate the temperature and time required to completing the ignition test $[16,17]$. Generally, higher temperatures increase the amount of aggregate mass loss and lower test temperatures may excessively increase the test time. $\mathrm{Li}, \mathrm{Yu}$ work [18] showed that different samples of asphalt content $\{\mathrm{AC}-10$ (penetration grade of 70/90), AC-20 (penetration grade of 60/70), and AC-40(penetration grade of 30/50) \} could be completely burned at temperature of $485^{\circ} \mathrm{C}$ and higher.

120 samples of HMA mixture of different types of aggregate with respective gradation type at various asphalt contents were prepared and tested under different temperature settings (from $490^{\circ} \mathrm{C}$ to $600^{\circ} \mathrm{C}$ with increment of $5^{\circ} \mathrm{C}$ ). The duration of ignition cycle (test time: the time required to achieve a constant mass) was established by manually measuring the sample's mass outside the oven to determine when a constant mass has been achieved (the samples were burned until the measured mass loss did not exceed 0.1 gram for five consecutive minutes).

As shown in Figure 1, the results of this work showed that the test time decreased greatly when the temperature was increased up to $535^{\circ} \mathrm{C}$. The test time reduced slightly when the temperature was increased above $550^{\circ} \mathrm{C}$. According to these results, a temperature setting of $535^{\circ} \mathrm{C}$ was initially selected as the optimum temperature of ignition test with optimum test time of 30 minutes.

\section{Study Results and Discussion}

The collected test data was analyzed and the accuracy and precision values for the HMA properties were calculated using statistical methods. Statistica Software(Version 6) was used to perform the statistical method of comparison on the deviations and significant of measured asphalt content and aggregate gradation. 


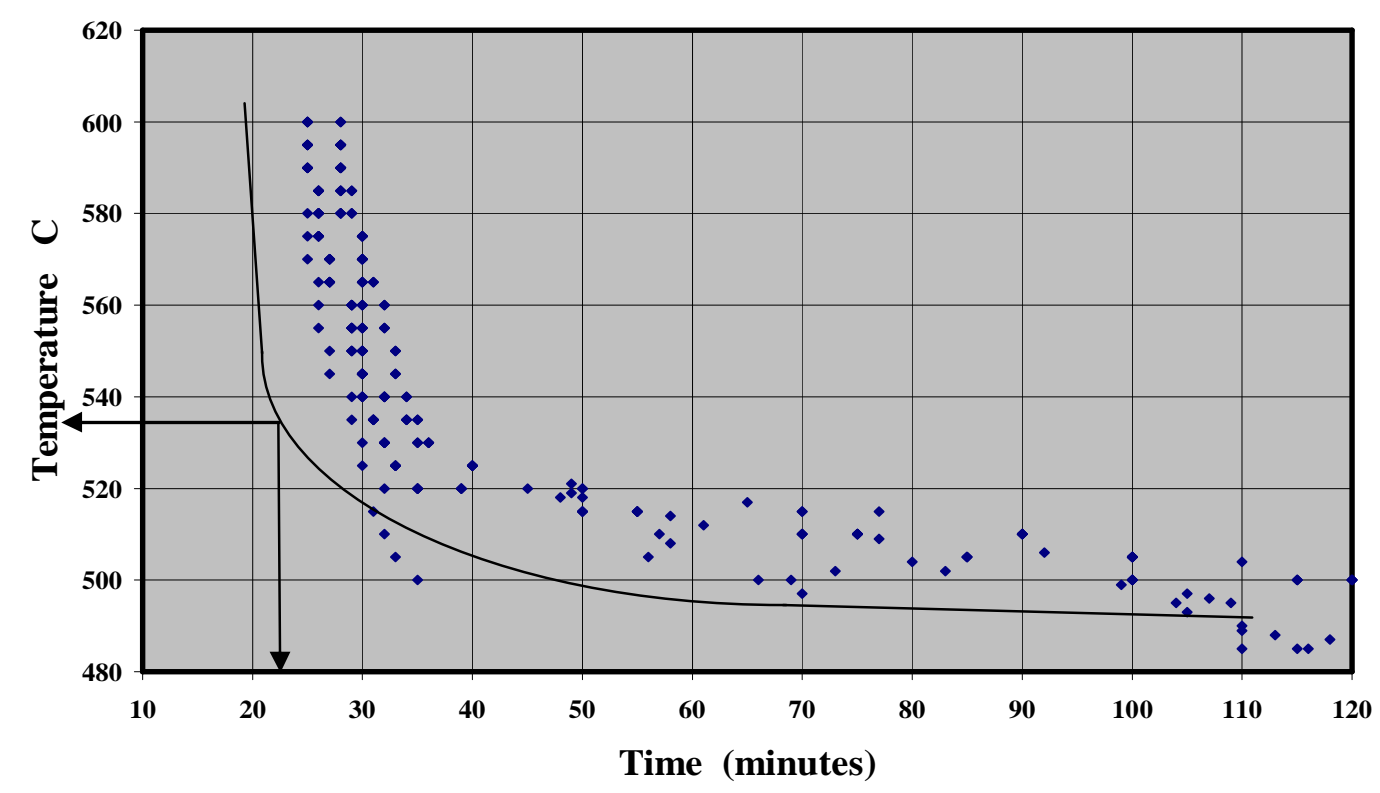

Figure 1. Selection of Optimum Temperature and Time of Ignition Test.

\section{Asphalt Content :}

The average deviation (bias) of measured asphalt content from the true asphalt content provides a good indication of the accuracy for determining asphalt content by the ignition method. Also, this deviation is a function of aggregate mass loss. The standard deviation (Stdev.) is a function of precision of measured test results[9,19,20].

The measured test results for ten laboratories were analyzed and summarized as data used for statistical comparison according to asphalt content, aggregate type and gradation type. Table 3 presents sample of these data computed for $4.5 \%$ asphalt content and gravel type of type II gradation. These data indicate that for the samples tested, the ignition test samples are within the tolerances normally used in Iraqi specifications.

The results of the ignition and centrifuge measured tests are summarized in Table 4 . This table shows the average deviation of measured asphalt content from the true asphalt content and the standard deviation for each aggregate type and gradation. These results were used to evaluate the accuracy and variability of the measured asphalt contents for the two tests. The accuracy of the asphalt contents is measured by the deviation or the difference between the measured and true asphalt content of the samples. While, the variability is measured by the standard deviation of the test results. For both test methods results and as shown in this table, most of the deviation values were positive (may be due to degradation problems). The total average deviation (0.00101) for centrifuge test was greater than the total average deviation $(0.00024)$ for the ignition test, while the standard deviation for the ignition test (0.00049) was slightly less than the standard deviation for the centrifuge test $(0.00056)$.

The ignition tests results show that all of the measured asphalt contents for the three repetitions of the total HMA mixtures are very close to the true asphalt contents. So for a total of all tests, the measured asphalt content deviation of the worst test from the true asphalt content was (0.00062). The low deviation measured indicates that the asphalt content of HMA mixtures can be obtained with a high degree of accuracy using ignition test method. 


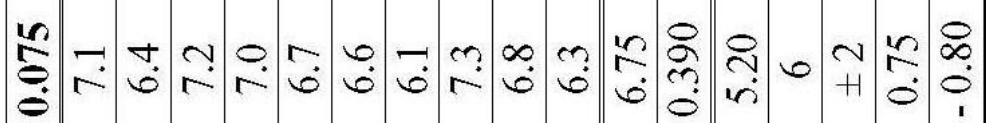

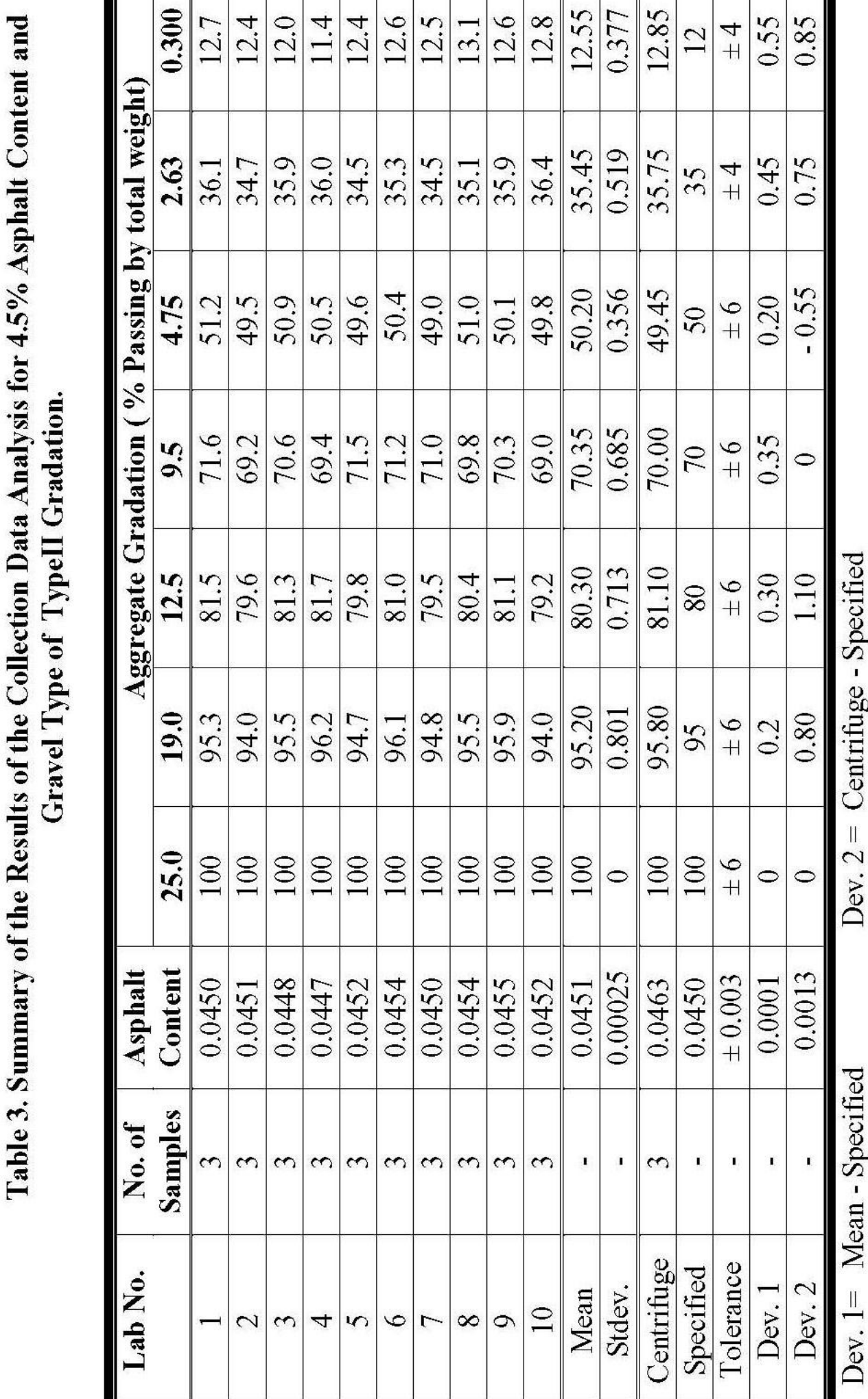




\section{Aggregate Mass Loss :}

As shown in Tables 4 and 5, with calibration (use of $C_{F}$ in the calculation) the aggregate type or gradation type did not have an appreciable effect on the deviation of measured asphalt content from the true asphalt content. For gravel and limestone mixtures, the average deviations were 0.00031 and 0.00028 for the Type I, 0.00019 and 0.00026 for Type II, and $0.00020,0.00022$ for Type IIIA mixtures, and 0.00023 and 0.00025 for total average respectively.

In this work, mixture composed of limestone appears to have more aggregate mass loss on ignition than the mixture composed of gravel. Based on these results, it appears that a correction factor would be required for some types of aggregate (the limestone type used in this study) to account for determining asphalt content by this method. On the contrary, the asphalt content determinations can be performed on other types of aggregate (the gravel type used in this study) without calibration.

To evaluate the need for calibration to find a correction factor in asphalt content determination by ignition method, the correction factor was excluded as shown in Table 5 . This table supports the contention that the calibration or correction is essential in this test method and must be performed on HMA samples to increase the accuracy of asphalt content determination.

Analysis of Variance(ANOVA) was used to statistically analyze the difference in correction factors for aggregate loss. As shown in Table 6, the aggregate correction factor or deviation of the measured asphalt content with and without calibration was used as the response variable, while asphalt content (6 levels), aggregate type (2 types) and gradation (3 types)were the effects factors. The analysis shows the followings :

1. There was a statistically significant difference between the test result deviations of the measured asphalt content without calibration from the true content for the two aggregate types and three gradation types. While, the five asphalt content levels did not statistically affect these deviations.

Table 4. Deviation and Standard Deviation of the Measured Asphalt Content by Test Type and Aggregate Type and Gradation.

\begin{tabular}{|c|c|c|c|c|c|c|c|c|}
\hline \multirow{3}{*}{ 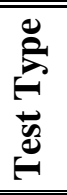 } & \multirow{3}{*}{$\begin{array}{c}\text { Actual } \\
\text { Asphalt } \\
\text { Content } \\
\%\end{array}$} & \multicolumn{6}{|c|}{ Deviation (Measured - Actual) } & \multirow{3}{*}{$\begin{array}{c}\text { Total } \\
\text { Average }\end{array}$} \\
\hline & & \multicolumn{3}{|c|}{ Gravel } & \multicolumn{3}{|c|}{ Limestone } & \\
\hline & & Type I & Type II & $\begin{array}{l}\text { Type } \\
\text { IIIA }\end{array}$ & Type I & Type II & $\begin{array}{l}\text { Type } \\
\text { IIIA }\end{array}$ & \\
\hline \multirow{7}{*}{ 宫 } & 3.5 & 0.00031 & $-\overline{--}$ & $-\overline{--}$ & 0.00035 & --- & 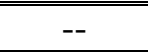 & 0.00033 \\
\hline & 4.0 & 0.00034 & 0.00030 & 0.00024 & || 0.00044 & 0.00031 & 0.00026 & 0.00031 \\
\hline & 4.5 & 0.00042 & 0.00010 & 0.00022 & 0.00036 & 0.00029 & 0.00019 & 0.00026 \\
\hline & 5.0 & 0.00019 & 0.00015 & 0.00015 & -0.00002 & 0.00024 & 0.00020 & 0.00015 \\
\hline & 5.5 & -- & 0.00022 & 0.00019 & -- & 0.00021 & 0.00024 & 0.00021 \\
\hline & Avg. & 0.00031 & 0.00019 & 0.00020 & 0.00028 & 0.00026 & 0.00022 & 0.00024 \\
\hline & Stdev. & 0.00045 & 0.00027 & 0.00064 & 0.00055 & 0.00063 & 0.00039 & 0.00049 \\
\hline \multirow{7}{*}{ 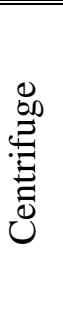 } & 3.5 & 0.00092 & -- & -- & 0.00108 & -- & -- & 0.00100 \\
\hline & 4.0 & 0.00083 & 0.00098 & 0.00098 & 0.00075 & 0.00085 & 0.00111 & 0.00092 \\
\hline & 4.5 & 0.00103 & 0.00130 & 0.00089 & 0.00109 & 0.00092 & 0.00104 & 0.00104 \\
\hline & 5.0 & 0.00115 & 0.00104 & 0.00097 & 0.00093 & 0.00105 & 0.00101 & 0.00102 \\
\hline & 5.5 & -- & 0.00091 & 0.00104 & -- & 0.00082 & 0.00143 & 0.00105 \\
\hline & Avg. & 0.00098 & 0.00106 & 0.00097 & 0.00096 & 0.00091 & 0.00115 & 0.00101 \\
\hline & Stdev. & 0.00063 & 0.00054 & 0.00050 & 0.00047 & 0.00056 & 0.00069 & 0.00056 \\
\hline
\end{tabular}


Table 5. Statistical Analysis and Comparison of Average Deviation Of Asphalt Content With and Without Aggregate Loss Correction.

\begin{tabular}{|c|c|c|c|c|c|}
\hline \multirow{3}{*}{\multicolumn{2}{|c|}{$\begin{array}{c}\text { Aggregate } \\
\text { Type and } \\
\text { Gradation }\end{array}$}} & \multicolumn{4}{|c|}{ Asphalt Content Determination } \\
\hline & & \multicolumn{2}{|c|}{ With Correction } & \multicolumn{2}{|c|}{ Without Correction } \\
\hline & & $\begin{array}{l}\text { Average } \\
\text { Deviation }\end{array}$ & $\begin{array}{c}\text { F-value } \\
\text { Calculated }\end{array}$ & $\begin{array}{l}\text { Average } \\
\text { Deviation }\end{array}$ & $\begin{array}{c}\text { F-value } \\
\text { Calculated }\end{array}$ \\
\hline \multirow{3}{*}{ 预 } & Type I & 0.00031 & 1.18 & 0.00078 & $3.44 *$ \\
\hline & Type II & 0.00019 & 0.93 & 0.00055 & 2.51 \\
\hline & Type IIIA & 0.00020 & 0.78 & 0.00051 & 2.18 \\
\hline \multirow{3}{*}{ 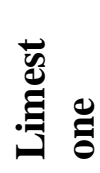 } & Type I & 0.00028 & 1.85 & 0.00255 & $7.88 * *$ \\
\hline & Type II & 0.00026 & 1.05 & 0.00183 & $5.98 * *$ \\
\hline & Type IIIA & 0.00022 & 0.99 & 0.00135 & $3.75 *$ \\
\hline
\end{tabular}

* Significant at the $1 \%$ significance level.

** Significant at the 5\% significance level.

2. The aggregate type and gradation are all significant factors for correction factor. This result indicates that, a separate correction factor should be determined for each aggregate type and gradation.

3. No obvious relationship exists between asphalt content and aggregate mass loss of HMA samples. Where, the statistical comparison indicates that statistically significant difference do not exist between the deviation of measured asphalt content from the true asphalt content for blank aggregate samples and those samples having asphalt cement added to aggregate.

4. All interactions between aggregate type, gradation type, and asphalt content are not significant factors for aggregate correction factor at the 5\% significance level. While the interaction between aggregate type and gradation is the only significant factor at the $1 \%$ significance level.

\section{Aggregate Gradation:}

The aggregate was recovered after ignition test and evaluated to determine if there was a significant change in gradation due to the test temperature.

The comparison was performed on the $12.5 \mathrm{~mm}, 4.75 \mathrm{~mm}, 0.30 \mathrm{~mm}$, and $0.075 \mathrm{~mm}$ sieves as critical sieve sizes ( these sieves will give a good indication of the effect on the remaining sieve sizes). The values of percent passing these sieves before and after the ignition test were analyzed to determine the effect of ignition test method on gradation. The accuracy (deviation: \% passing after test minus \% passing before test) and precision ( standard deviation) of the percent passing the critical sieves were computed for each asphalt content and gradation type as shown in Table 7 . These results were match the findings of most previous works and studies[6,9,13, 19,21,22].

The differences in the deviation of percent passing each critical sieve, especially the $0.075 \mathrm{~mm}$ sieve, between aggregate types mixed with asphalt cement can be explained by the abrasion resistance of each aggregate type. Limestone aggregate, unlike gravel, is not as resistant to abrasion and degraded during the mixing operations. Moreover, these differences between aggregate sample without asphalt content $(0.0 \%)$ and asphalt mixture samples (those prepared with other asphalt contents) for both aggregate types support the degradation problem due to abrasion during mixing operations. Where, the aggregate samples that were 
mixed with asphalt cement were affected by aggregate degradation due to abrasion. The deviations and standard deviations of the percent passing the $4.75 \mathrm{~mm}$ sieve are very low, Therefore, the percent passing this sieve size can be determined with a high degree of accuracy and precision.

Table 6. Analysis of Variance on Aggregate CorrectionFactors

\begin{tabular}{|c|c|c|c|c|}
\hline \multirow{2}{*}{$\begin{array}{c}\text { Affecting } \\
\text { Factors }\end{array}$} & \multirow{2}{*}{$\begin{array}{l}\text { Degree of } \\
\text { Freedom }\end{array}$} & \multirow{2}{*}{$\begin{array}{c}\text { F-value } \\
\text { Calculated }\end{array}$} & \multicolumn{2}{|c|}{ Significance Level } \\
\hline & & & $1 \%$ & $5 \%$ \\
\hline A & 1 & 63.59 & Yes & Yes \\
\hline B & 2 & 25.68 & Yes & Yes \\
\hline $\mathrm{C}$ & 5 & 1.33 & No & No \\
\hline $\mathrm{A}^{*} \mathrm{~B}$ & 2 & 3.47 & Yes & No \\
\hline $\mathrm{A}^{*} \mathrm{C}$ & 5 & 1.04 & No & No \\
\hline $\mathrm{B} * \mathrm{C}$ & 10 & 0.81 & No & No \\
\hline $\mathrm{A} * \mathrm{~B} * \mathrm{C}$ & 10 & 1.20 & No & No \\
\hline Error & 72 & & & \\
\hline Total & 107 & & & \\
\hline
\end{tabular}
A : Aggregate Type
B : Gradation Type
C: Asphalt Content

Table 7. Accuracy and precision of Ignition Test for Percent Passing the Critical Sieves According to Aggregate Type and Asphalt Content.

\begin{tabular}{|c|c|c|c|c|c|c|c|c|}
\hline \multirow{2}{*}{\multicolumn{2}{|c|}{$\begin{array}{l}\text { Aggregate } \\
\text { Type and } \\
\text { Gradation }\end{array}$}} & \multicolumn{6}{|c|}{$\begin{array}{c}\text { Deviation of \% Passing ( After Test - Before Test) } \\
\text { According to Asphalt Content \% }\end{array}$} & \multirow[t]{2}{*}{$\begin{array}{l}\text { Standard } \\
\text { Deviation }\end{array}$} \\
\hline & & 0.00 & 3.50 & 4.00 & 4.50 & 5.00 & 5.50 & \\
\hline \multirow{5}{*}{ D্ } & $12.5 \mathrm{~mm}$ & 0.050 & 0.155 & 0.135 & 0.140 & 0.155 & 0.165 & \\
\hline & $4.75 \mathrm{~mm}$ & 0.035 & 0.070 & 0.095 & 0.085 & 0.080 & 0.095 & 21 \\
\hline & $0.30 \mathrm{~mm}$ & 0.060 & 0.170 & 0.185 & 0.180 & 0.190 & 0.175 & \\
\hline & $0.075 \mathrm{~mm}$ & 0.095 & 0.185 & 0.175 & 0.195 & 0.195 & 0.185 & \\
\hline & Average & 0.060 & 0 . & 0.148 & 0.150 & 0.155 & 55 & \\
\hline \multirow{5}{*}{ 苞 } & $12.5 \mathrm{~mm}$ & 0.190 & 0.295 & 0.315 & 0.300 & 0.280 & 0.325 & 45 \\
\hline & $4.75 \mathrm{~mm}$ & 0.135 & 0.195 & 0.205 & 0.225 & 0.215 & 0.215 & \\
\hline & $0.30 \mathrm{~mm}$ & 0.325 & 0.535 & 0.545 & 0.530 & 0.555 & 0.560 & 0.083 \\
\hline & $0.075 \mathrm{~mm}$ & 0.375 & 0.740 & 0.755 & 0.755 & 0.770 & 0.765 & 0.143 \\
\hline & Average & 0.255 & 0.445 & 0.450 & 0.455 & 0.455 & 0.465 & 0.075 \\
\hline
\end{tabular}

As shown in Table 8, ANOVA is used to determine the factors that significantly affect the difference between the average percent passing each critical sieve size before and after ignition test. Asphalt content (5 levels), aggregate type (2 types), and aggregate gradation (3 types) are the factors. The ANOVA results show the followings :

1. Aggregate type, aggregate gradation, and the interaction between them ar esignificant for $5 \%$ significance level for all critical sieve sizes, and significant for $1 \%$ significance level for $0.075 \mathrm{~mm}$ sieve size. The effect of these factors will be changed (more accuracy and precision) when the correction factor for aggregate mass loss was used in calibration the percent passing each sieve size after ignition test as follow: 
a. multiply by $\mathrm{C}_{\mathrm{F}}$ when the average deviation was positive value

b. multiply by $1 / \mathrm{C}_{\mathrm{F}}$ when the average deviation was negative value.

2. Asphalt content and its interactions are not significant factors for any of the critical sieve sizes.

Table 8 . Analysis of Variance on Deviation of the Percent Passing the Critical Sieves.

\begin{tabular}{|c|c|c|c|c|c|}
\hline \multirow{2}{*}{$\begin{array}{l}\text { Affecting } \\
\text { Factors }\end{array}$} & \multirow{2}{*}{$\begin{array}{l}\text { Degree of } \\
\text { Freedom }\end{array}$} & \multicolumn{4}{|c|}{ F-value calculated According to sieve size } \\
\hline & & $19 \mathrm{~mm}$ & $4.75 \mathrm{~mm}$ & $0.30 \mathrm{~mm}$ & $0.075 \mathrm{~mm}$ \\
\hline A & 1 & $3.93 *$ & $3.51 *$ & $12.74 * *$ & $34.88 * *$ \\
\hline $\mathrm{B}$ & 2 & $2.28^{*}$ & $2.66^{*}$ & $9.52 * *$ & $15.94 * *$ \\
\hline $\mathrm{C}$ & 5 & 0.88 & 0.90 & 1.37 & 1.44 \\
\hline $\mathrm{A}^{*} \mathrm{~B}$ & 2 & $2.22 *$ & $2.83 *$ & $3.55^{*}$ & $7.49 * *$ \\
\hline $\mathrm{A}^{*} \mathrm{C}$ & 5 & 1.09 & 1.30 & 1.44 & 1.75 \\
\hline $\mathrm{B} * \mathrm{C}$ & 10 & 0.85 & 0.57 & 0.97 & 1.21 \\
\hline $\mathrm{A} * \mathrm{~B} * \mathrm{C}$ & 10 & 0.90 & 0.94 & 1.05 & 1.44 \\
\hline Error & 72 & & & & \\
\hline Total & 107 & & & & \\
\hline
\end{tabular}

A : Aggregate Type B : Gradation Type

* Significant at the $1 \%$ significance level.

** Significant at the 5\% significance level.

\section{Conclusions and Recommendations}

The ignition test method is really quite simple. The asphalt in an oven will be burnt off, leaving clean aggregate which can be analyzed for gradation. The loss in mass resulting from burn is related to asphalt content. Based on the results presented in this study, the following conclusions and recommendations can be drawn:

1. The ignition test method can be significantly used to determine the asphalt content and aggregate gradation of HMA mixtures. Compared to the solvent extraction test method, the ignition test method :

a) Is faster, safer and inexpensive (cost saving).

b) Has significant lower deviation and standard deviation of measured asphalt content from the true asphalt content and therefore provides a higher degree of accuracy and precision.

2. During the ignition test, the aggregate used in HMA samples experiences an apparent loss. Therefore, the correction factors for aggregate mass loss are used to evaluate the accuracy and repeatability of the measured asphalt content (ensure that an aggregate loss is not counted as burned off asphalt).

3. It is recommended that the ignition test method can be implemented for use on HMA mixture works, studies and projects in Iraq as appropriate method for asphalt content and aggregate gradation determinations at a temperature of $535^{\circ} \mathrm{C}$ for 30 minutes.

4. The ignition test method can be performed in Iraq as a procedure for simply evaluating the HMA mixtures. It can be used for official laboratories performing independent assurance, verification, quality control and acceptance testing.

5. More laboratory and field experiments (research and development efforts) will be required to evaluate the ignition method under all conditions and with various paving materials used in Iraq. 


\section{References}

1. Casola, J., 2005," Asphalt Binder Testing Equipment Offers Help Meeting Specifications ", Bohlin Instruments Inc., Cranbury, N. J. , U.S.A.

2. National Center of Asphalt Technology, 1995, " Asphalt Content Test Offers Improvement Over Solvents", TR News180, Alabama , U.S.A.

3. Hurley, G. C. and Prowell, B. D., 2003,"Evaluation of Infrared Ignition Furnace for Determination of Asphalt Content",Paper Submitted to the 82 nd Annual Meeting of the Transportation Research Board , U.S.A.

4. Asphalt Content Tester,2000,"A New Method for Quality Control of Asphalt Mixture", ELE International Ltd., England.

5. Murphy, N. E., 1994,"Asphalt Content Determination by the Ignition Method", Thesis for Degree of Master of Science, Auburn University, AL, U.S.A.

6. Brown, E. R., Murphy, N.E., Li, Yu and Mager, S., 1995," Historical Develop- ment of Asphalt Determination by Ignition Method" , Journal of Asphalt Paving Technologists, Vol. 64, FL., U.S.A.,pp42.

7. Brown, E. R. and Mager, S., 1995," Asphalt Content by Ignition Round Robin Study", National Center for Asphalt Technology, Report No. 95-3.

8. Federal Highway Administration, 1999,"Method for Determining the Asphalt Content of Hot Mix Asphalt by the Ignition Method", FHWA Multi- regional Asphalt Training \& Certification Group, U.S.A.

9. California Department of Transportation, 2001 , Determination of Asphalt Content of Bituminous Mixtures by the Ignition Method ", Test 382, California, U.S.A.

10. American Society for Testing and Materials(ASTM), 2004,"Annual Book of ASTM Standards", PA. , U.S.A.

11. American Association of State Highway and Transportation Officials, 2001, "Determining the Asphalt Binder Content of Hot Mix Asphalt by the Ignition Method",AASHTO Designation:T308-05,Washington,D.C.,U.S.A.

12. Republic of Iraq, Ministry of Housing and Construction, 2003 , "General Specification for Roads and Bridges", Revised Edition 2003, Department of Planning and Studies, Iraq.

13. Gordon Mc. Keen, P. E., 1997, " Asphalt Content by Ignition Round-Robin Experiment", New Mexico State Highway and Transportation Department, Santa Fe, New Mexico .

14.Saskatchewan Highway and Transportation, 2004,"Asphalt Content by Ignition Oven Instructions to Participants",Canadian Asphalt Mix Exchange program, Saskatchewan, Canada.

15. AUSTRODS National Asphalt Research Coordination Group, 2003, "Asphalt Binder Content: Ignition Oven Method", Asphalt Test 04, Australian.

16. Indiana Department of Transportation, 2005,"Asphalt Binder Content by Igni- tion", Materials and Tests Division, ITM No. 586-02 T, Indiana, U.S.A.

17. Williams, S.G. and Hall, K.D., 2001," A Comparison of Ovens for Determining The Binder Content by the Ignition Method ", Journal of Asphalt Paving Technologists, Vol.70, FL., U.S.A.,pp.18.

18. Li , Yu , 1992, " Determination of Asphalt Content and Aggregate Gradation of HMA by Ignition Heating", Thesis for Degree of Master of Science, Auburn University, AL, U.S.A.

19. Suvorovs, T. and et. al. , 2007 , "Statistical Evaluation of Promote Ignition Test Data", Journal of ASTM International, Vol.4, Issue 7.

20. Harris, N. J., Horer, K.C., Folliard, K.J. and Ley, T., 2006,"Variables Affecting the ASTM Standard C 311 Loss on Ignition Test for Fly Ash ", Journal of ASTM International, Vol.3, Issue 8, U.S.A.,pp.12.

21. New Hampshire Department of Transportation, 1995, " Asphalt Content Determination by the Ignition Ovens", Bureau of Materials and Research, N.M., U.S.A.

22. MN / Department of Transportation , 2004, " Determination of the Asphalt Binder Content of Hot Mix Asphalt by the Ignition Method", Laboratory Manual 1853, M.N., U.S.A.

The work was carried out at the college of Engg. University of Mosul 